УДК 69

\title{
ПЕРСПЕКТИВЫ ИСПОЛЬЗОВАНИЯ ОТКРЫТОГО ФОРМАТА ІFС ДЛЯ ОБЕСПЕЧЕНИЯ ПРОЦЕССА ОБМЕНА ДАННЫМИ В ЦИФРОВОЙ ИНФОРМАЦИОННОЙ МОДЕЛИ
}

\author{
Панов Александр Валерьевич \\ магистрант
}

Научный руководитель: Игнатьев Александр Владимирович д.т.н, доцент

Институт архитектуры и строительства ФГБОУ ВО «Волгоградский государственный технический университет»

Аннотация: рассмотрена эффективность и целесообразность использования формата IFC для обеспечения процесса обмена данными в цифровой информационной модели между программными продуктами разных производителей.

Ключевые слова: цифровая информационная модель, ВІМ, коллизия, IFC.

\section{PROSPECTS FOR USING THE OPEN IFC FORMAT TO SUPPORT THE DATA EXCHANGE PROCESS IN THE DIGITAL INFORMATION MODEL}

Panov Alexander Valerevich Scientific adviser: Ignatyev Alexander Vladimirovich

\begin{abstract}
IFC format to ensure the process of data exchange in the digital information model between software products of different manufacturers is considered.

Key words: digital information model, BIM, collision, IFC.

5 марта 2021 года Правительство РФ приняло постановление, согласно которому с 1 января 2022 года все объекты госзаказа должны проектироваться и строиться только с формированием и ведением информационной модели объекта капитального строительства, т.е. с применением ВІМ-технологии [1].
\end{abstract}


Современный рынок предлагает множество продуктов для реализации ВIM-проектирования, 90\% из которых на Российском рынке представлены продукцией компании Autodesk. При этом инженерные данные, создаваемые САПР, реализующих ВІМ-моделирование, в большинстве случаев имеют проприетарные, т.е. закрытые коммерческие форматы, специфичные для их собственных программных продуктов, и не являются общими в прямом смысле этого слова. Поэтому для создания и поддержания среды общих данных в процессе архитектурно-строительного проектирования необходимо использовать открытые форматы.

Одним из таких форматов является IFC (Industry Foundation Classes) формат файлов, который позволяет обмениваться данными между различными приложениями [2]. Этот формат определяет международные стандарты импорта и экспорта объектов-зданий и их свойств.

В ряде нормативных документов, например [3] и [4], именно этот стандарт рекомендуется использовать для трехмерной модели в составе информационной модели объекта капитального строительства.

В частности, в СП 333.1325800.2017 «Информационное моделирование в строительстве. Правила описания компонентов информационной модели», для передачи цифровой информационной модели рекомендуется использовать формат с открытой спецификацией IFC (версии $2 \times 3$ и выше).

Нами было рассмотрено, насколько эффективным является использование формата IFC для обеспечения процесса обмена данными в цифровой информационной модели между программными продуктами разных производителей.

В качестве программных продуктов, участвующих в процессе обмена данными в цифровой информационной модели, нами были ввыбраны Revit от компании Autodesk и Renga от компании «Аскон».

Для эксперимента была взята модель двухэтажного коттеджа с ленточным фундаментом, материалом стен из монолитного железобетона, двускатной, черепичной крышей и монолитными безбалочными перекрытиями.

Модель, созданная в Revit, была импортирована в формат IFC 4.0, а потом полученная IFC-модель была открыта в этом же программном продукте. На рис.1 можно результат этой операции. Отсутствуют некоторые стены, лестница, не все файлы можно редактировать.

Далее эта же IFC-модель была открыта в Renga. Здесь стены на месте, но не все имеют свойства, а также некоторые элементы собраны в группы, как это можно увидеть на рис.2. 


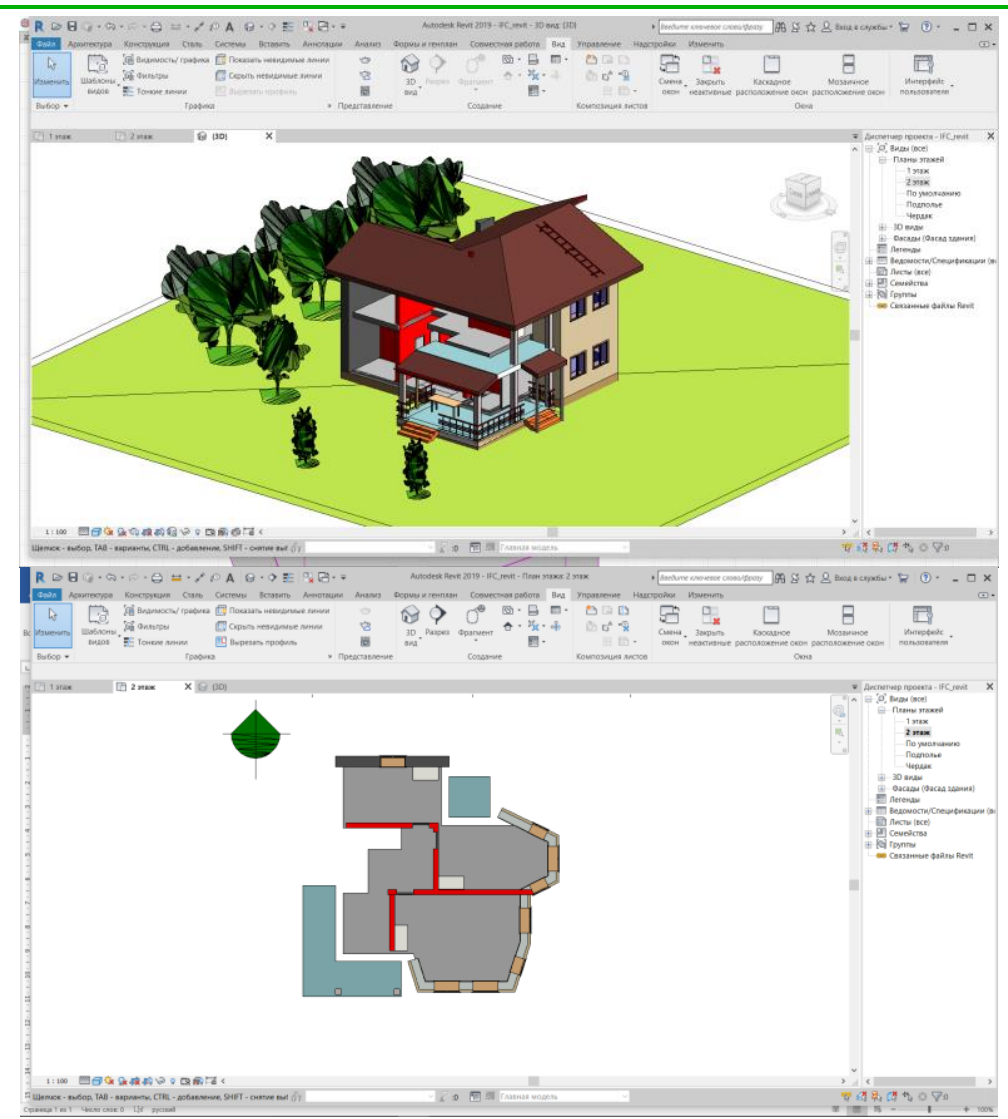

Pис. 1. Проект, созданный в Revit, импортирован в IFC и открыт в Revit

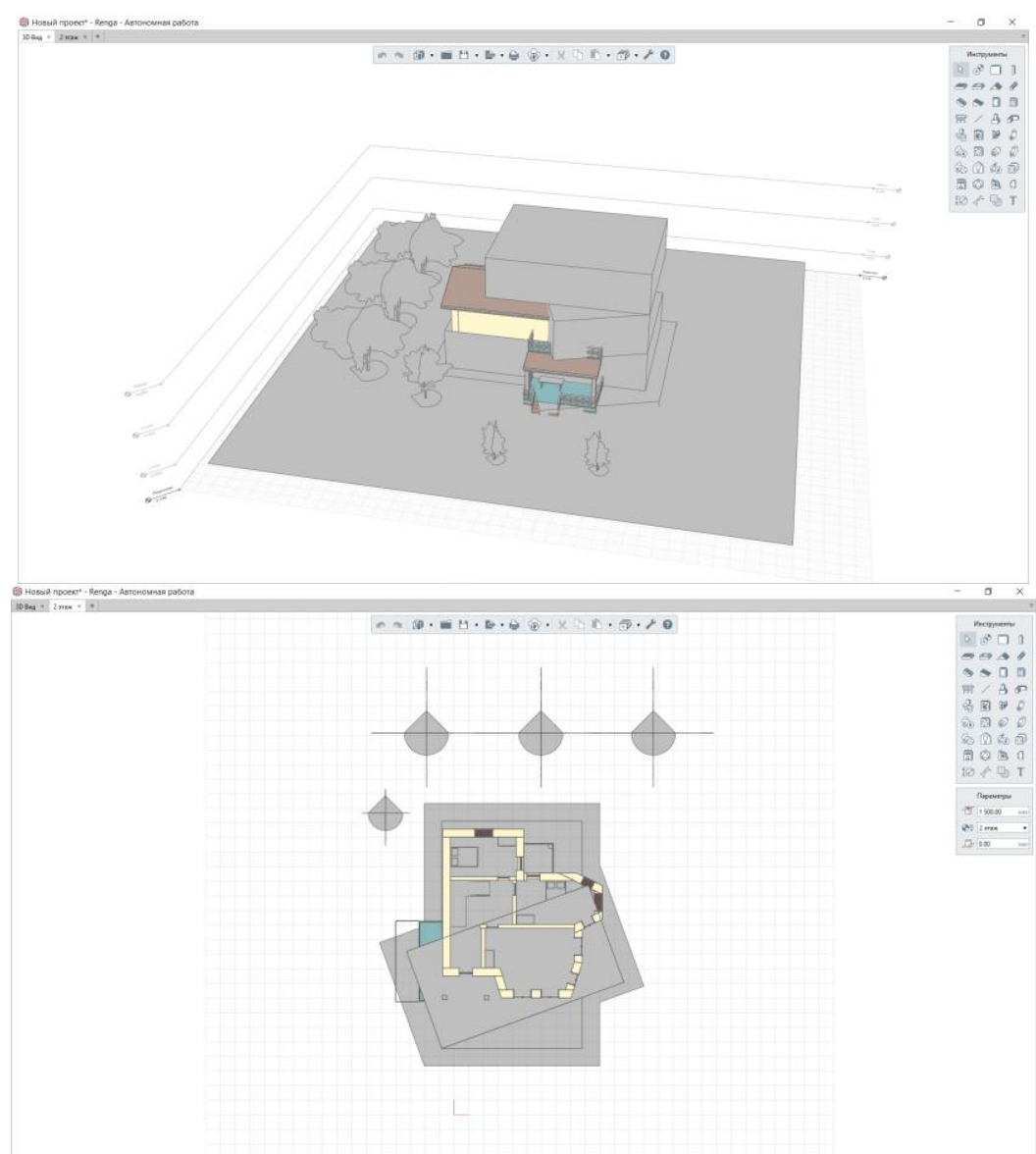

Рис. 2. Проект, созданный в Revit, импортирован в IFC и открыт в Renga 41 
Аналогично за основу был взят аналогичный проект, созданный в Renga, и также импортирован в IFC 4.0.

Полученная IFC-модель была сначала открыта в Renga. У открытой модели редактируемые объекты. На 3d виде присутствуют все элементы, но на рис. 3 можно увидеть, что на планах отсутствуют стены, витражи, лестницы.

Когда IFC-проект, созданный в Renga, был открыт в Revit, то стало видно, что в модели присутствуют планы, но на видовых экранах утеряны объекты (рис. 4).

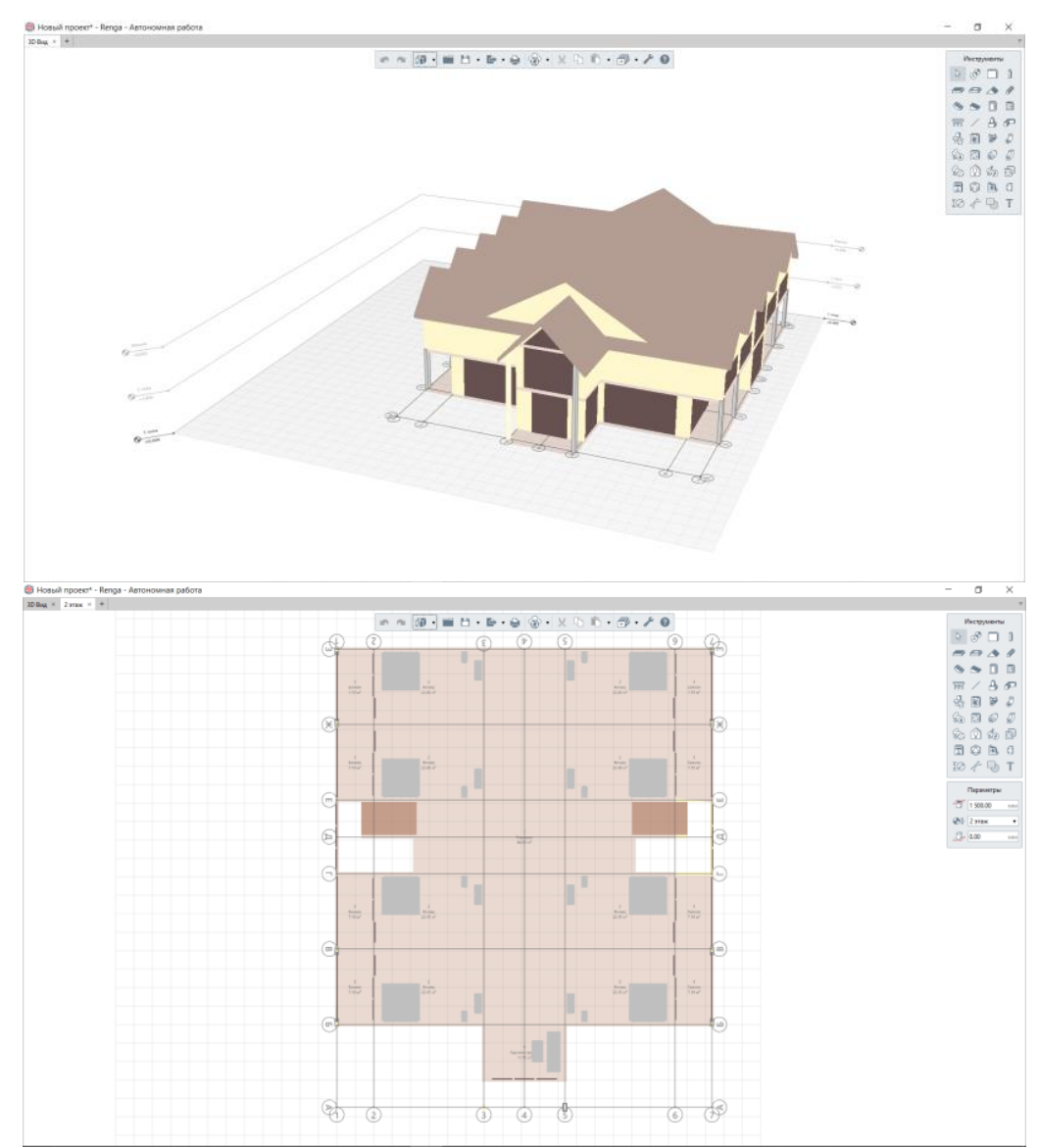

Рис. 3. Проект, созданный в Renga, импортирован в IFC и открыт в Renga

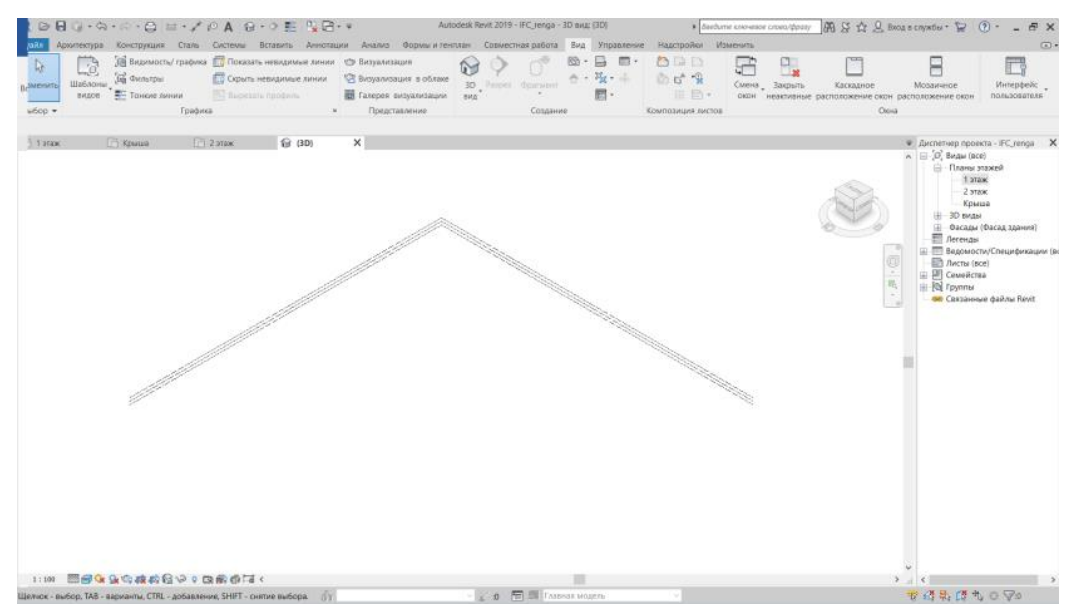

Рис. 4. Проект, созданный в Renga, импортирован в IFC и открыт в Revit 
Проведенный нами эксперимент показал, что формат IFC не дает полной идентичности проекта, так как в каждом программном продукте присутствуют структурные элементы, которые необходимо настраивать вручную перед экспортом. Так же есть потери в модели и не всегда есть возможность редактирования объектов. IFC формат имеет больший размер файла исходника, что приводит к длительному открытии в САПР.

Модели в файле посреднике не подходят для дальнейшей работы в других САПР. Если возникнет такая задача, то оптимальным будет воспользоваться API, набора способов прямой передачи данных между различными САПР. Файл-посредник IFC же, может служить в качестве вспомогательного изображения, подложки.

\section{Список литературы}

1. Постановление Правительства Российской Федерации "Об установлении случая, при котором застройщиком, техническим заказчиком, лицом, обеспечивающим или осуществляющим подготовку обоснования инвестиций, и (или) лицом, ответственным за эксплуатацию объекта капитального строительства, обеспечиваются формирование и ведение информационной модели объекта капитального строительства" от 05.03.2021 № $331 / /$ Парламентская газета.

2. IFC Specifications Database // buildingSMART International URL: https://technical.buildingsmart.org/standards/ifc/ifc-schema-specifications/ (дата обращения: 12.04.2021).

3. Постановление Правительства Российской Федерации "Об утверждении Правил формирования и ведения информационной модели объекта капитального строительства, состава сведений, документов и материалов, включаемых в информационную модель объекта капитального строительства и представляемых в форме электронных документов, и требований к форматам указанных электронных документов, а также о внесении изменения в пункт 6 Положения о выполнении инженерных изысканий для подготовки проектной документации, строительства, реконструкции объектов капитального строительства" от 15 сентября 2020 г. № 1431 // Собрание актов Президента и Правительства Российской Федерации.

4. СП 333.1325800.2017 «Информационное моделирование в строительстве. Правила формирования информационной модели объектов на различных стадиях жизненного цикла» // Минстрой России URL: https://minstroyrf.gov.ru/docs/16405/ (дата обращения: 12.04.2021).

(C) А.В. Панов, 2021 